\title{
Time-Dependent Inhibition of Prostaglandins Synthesis by Nonsteroidal Antiinflammatory Drugs; Time-Dependent Alteration of Inhibitory Effect and Characteristics of its Active Site
}

\author{
Makoto MURAMATSU, Makoto TANAKA, Atsuko FUJITA, \\ Susumu OTOMO and Hironaka AIHARA \\ Taisho Pharmaceutical Co., Ltd, Research Center, Ohmiya, Saitama 330. Japan
}

Accepted January 23, 1984

\begin{abstract}
The characteristics of the time-dependency of nonsteroidal antiinflammatory drugs (NSAIDs) and their active sites in inhibiting cyclooxygenase activity were investigated using bovine seminal vesicle microsomal fraction. The Hill's coefficients of the inhibition curve of most NSAIDs were approximately 1.0 , except for some drugs which had Hill's coefficients that were obviously more than 1.0. The values for indomethacin, diclofenac and flurbiprofen were approximately 1.5 , 1.7 and 2.0, respectively. A time-dependent cyclooxygenase inhibiting effect was observed only with the NSAIDs in the group which had Hill's coefficients that were significantly more than 1.0. A time-dependent increase in inhibiting activity of these drugs was observed by the change in the inhibition curve. Timedependently, the Hill's coefficient of the curve of the NSAIDs approached 1.0 from more than 1.0. With this change, the shift of the curve to the left was also observed time-dependently. These changes in the curve were no longer seen when the Hill's coefficient dropped to 1.0. These time-dependent effects were protected by salicylic acid. which did not have any effect on cyclooxygenase activity in vitro, in a dose-dependent manner. These results suggested that the two classes of NSAIDs, time-dependent and non-time-dependent, are clearly differentiated by the slope of the inhibition curve of NSAIDs. Furthermore, the present results indicate that the degree of time-dependence of the NSAIDs depends on the Hill's coefficient of the inhibition curve, and the value is important for the potency of the cyclooxygenase inhibition, in addition to the affinity for the catalytic site of the enzyme.
\end{abstract}

Since the first report by Vane (1) on the inhibition of the biosynthesis of prostaglandins (PGs) by aspirin, many nonsteroidal antiinflammatory drugs (NSAIDs) have been shown to inhibit the key enzyme of PGs synthesis, namely cyclooxygenase. Among the many NSAIDs, some drugs showed time-dependent inhibition of cyclooxygenase activity (2-4). As one of the mechanisms of this time-dependent loss of activity, enzyme acylation by aspirin was reported, but this concept was not generally accepted for the mechanism of other time-dependent inhibitors, indomethacin and flurbiprofen. For another mechanism of the time-dependency of NSAIDs, Rome and Lands (4) indicated some structual requirement for the drugs.

On the other hand, the presence of two sites at which NSAIDs interact on cyclooxygenase were indicated by the effects of NSAIDs on PG synthesis (5). They interpreted these two sites as (1) a catalytic site which determines the potency of NSAIDs and (2) a supplementary site which is also obligatory for efficacy as a cyclooxygenase inhibitor, and further, they considered that the latter site may explain the selectivity in inhibiting cyclooxygenase rather than lipoxygenase.

In the present study, we characterized the 
time-dependent NSAIDs action in inhibiting the cyclooxygenase activity by kinetic analysis and showed the involvement of the supplementary site in the action of the NSAIDs.

\section{Materials and Methods}

The microsomal fraction of bovine seminal vesicle (Prostaglandin (PG) synthetase) was obtained from Miles Laboratories.

Assays of PG biosynthesis activity: The enzyme activity was measured by a slight modification of the method previously reported $(6,7)$. PG biosynthesis was carried out in $0.5 \mathrm{ml}$ of a reaction mixture consisting of $1 .{ }^{14} \mathrm{C}$-arachidonic acid (S.A.: $52.9 \mathrm{mCi}$ ) mmol, New England Nuclear), enzyme (100 / g protein), hematin (1//M), reduced glutathion (1 $\mathrm{mM})$, tryptophan $(1 \mathrm{mM})$ and $\mathrm{pH} 7.4$ potassium phosphate buffer $(50 \mathrm{mM})$. The reaction medium was incubated in the presence or absence of inhibitor at $30^{\circ} \mathrm{C}$. Ethanol was used to dissolve the arachidonic acid and inhibitors. The effect of ethanol on PG synthesis was not observed. Unless otherwise noted, $0.38 / / \mathrm{M}{ }^{14} \mathrm{C}$-arachidonic acid was used.

Inhibition of PG biosynthesis: The inhibition of cyclooxygenase activity by NSAIDs was investigated under the following two different incubation conditions: (1) No preincubation: The reaction was started by adding an aliquot of the enzyme at $30^{\circ} \mathrm{C}$. and (2) Preincubation: Inhibitors were preliminarily incubated with the enzyme in $50 \mathrm{mM}$ potassium phosphate buffer $(\mathrm{pH}$ 7.4) containing the cofactors for prostaglandins biosynthesis. Even under the condition with no NSAIDs, the enzyme activity was decreased only by incubation at $30^{\circ} \mathrm{C}$ when there was no arachidonic acid in the reaction mixture. However, the inhibition curves of NSAIDs were observed as under the condition of no preincubation with the enzyme.

Selective extraction and identification of PGs: The reaction was stopped by adding $2 \mathrm{ml}$ of $\mathrm{n}$-hexane-ethyl acetate $(2: 1, \mathrm{v} / \mathrm{v})$ according to the method of Yanagi and Komatsu (7). The remaining arachidonic acid in the reaction medium was extracted to the organic phase by mixing with $n$-hexaneethyl acetate. After centrifugation at $1,000 \times g$ for $10 \mathrm{~min}$, the aqueous phase was frozen at $-20^{\circ} \mathrm{C}$, and the organic solvent phase was discarded. The extraction was repeated three times. The resultant aqueous phase was mixed with $1.0 \mathrm{ml}$ ethanol to minimize the protein binding of radioactivity and centrifuged at $1,000 \times \mathrm{g}$ for $10 \mathrm{~min}$. Since $\mathrm{PGE}_{2}$ selectively remained in the aqueous phase, the $P G$ biosynthesis activity was determined by measuring the radioactivity in the aqueous phase with a liquid scintillation spectrometer (Packard TriCarb, model 3375). Under these reaction conditions, $\mathrm{PGE}_{2}$ was the main product which made up more than $93 \%$ of the total product. By this selective extraction, more than $90 \%$ of the $\mathrm{PGE}_{2}$ was recovered from the reaction medium.

${ }^{14} \mathrm{C}$-Indomethacin $\left({ }^{14} \mathrm{C}\right.$-IM) binding to PGs synthetase: The enzyme preparation was incubated with $5 / / M{ }^{14} \mathrm{C}$-IM (S.A.: 17.2 $\mathrm{mCi} / \mathrm{mmol}, \mathrm{RCC}$ Amersham) in a volume of $1.0 \mathrm{ml}$ at $23^{\circ} \mathrm{C}$ and filtered through a Millipore HAMP $(0.45 \mu \mathrm{m})$ filter. The radioactivity found in the presence of $2 \mathrm{mM}$ nonlabeled IM was considered to be nonspecifically bound ${ }^{14} \mathrm{C}-\mathrm{IM}$ and subtracted from each value in the absence of $2 \mathrm{mM} / \mathrm{M}$ to obtain the amount of specifically bound ${ }^{14} \mathrm{C}$-IM. The specific binding of ${ }^{14} \mathrm{C}-\mathrm{IM}$ increased linearly with the protein concentration up to $1.0 \mathrm{mg} /$ assay and reached equilibrium. However, this specific binding did not increase timedependently for $30 \mathrm{~min}$.

Enzyme solubilization: Bovine seminal vesicle microsomal fraction $(2.8 \mathrm{mg} / \mathrm{ml})$ was solubilized with $1 \%$ Nonidet $\mathrm{P}-40$ by standing for $20 \mathrm{~min}$ at $0^{\circ} \mathrm{C}$, and the resultant supernatant was centrifuged at $100,000 \times \mathrm{g}$ for $30 \mathrm{~min}$ and used as the enzyme preparation.

Protein concentration was determined by the method of Lowry et al. (8) using bovine serum albumin as a standard.

Drugs used: Ibuprofen (IP) (Hokuko), IM (Sumitomo), Phenylbutazone (PB) (Sigma), Diclofenac (DF) (Iwaki), BW755C (Welcome) and Salicylic acid (Wako Junyaku). Ketoprofen (KP), Flurbiprofen (FP). Alclofenac (AF). Flufenamic acid (FA), Benoxaprofen (BP) and Naproxen (NP) were prepared from commercial medicines in our laboratory. 


\section{Results}

Difference in inhibition pattern of nonsteroidal antiinflammatory drugs for prostaglandin synthesis: The prostaglandin (PG) synthesis was significantly inhibited by various nonsteroidal antiinflammatory drugs (NSAIDs) in a concentration dependent manner. Under the conditions involving $2 \mathrm{~min}$ incubation with non-preincubation, however, the inhibition curves of these drugs were not always parallel (Fig. 1). Hill plot analysis of the inhibition curve showed that the Hill's coefficient for most drugs was approximately 1.0. but the coefficient for some drugs were clearly more than 1.0 (Fig. 2). IP, PB, AF and $K P$ belonged to the former group, and $I M, D F$ and FP belonged to the latter group. The Hill's coefficients of IM, DF and FP were approximately $1.5,1.7$ and 2.0, respectively. The Hill's coefficients of other NSAIDs, NP, FA, BW755C and BP were nearly 1.0 (data not shown).

Three enzymes, cyclooxygenase, hydroperoxidase and $P G E_{2}$ synthetase, are involved in $\mathrm{PGE}_{2}$ synthesis from arachidonic acid ( 9 . 10). It is well known that various NSAIDs do not have any effect on hydroperoxydase (11). and in this study, the results showing that Hill's coefficients of the inhibition curves of NSAIDs were 1.0 or more than 1.0 indicate that the reaction is regulated by one main enzyme activity, so we used cyclooxygenase activity to represent the enzyme activity of PGs synthesis. Mizuno et al. (11) demonstrated that $P B$ inhibited the reaction of hydroperoxidase in addition to cyclo-

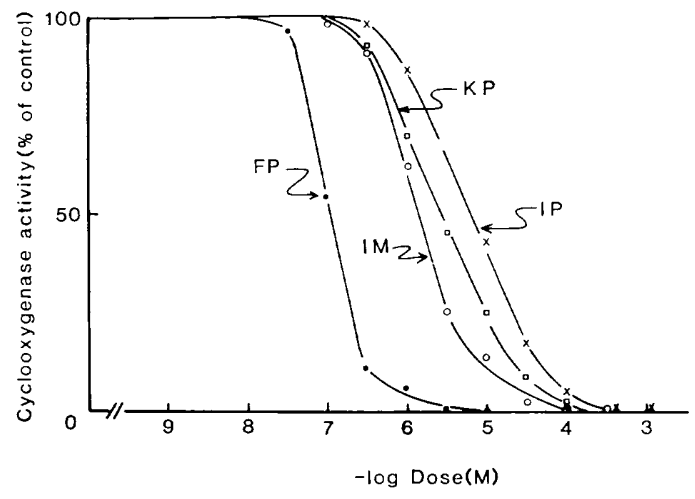

Fig. 1. Inhibition of cyclooxygenase activity by various NSAIDs. Specific activity of the control was $90.5 \pm 5.2 \mathrm{pmoles} / \mathrm{mg}$ protein $/ \mathrm{min}$.

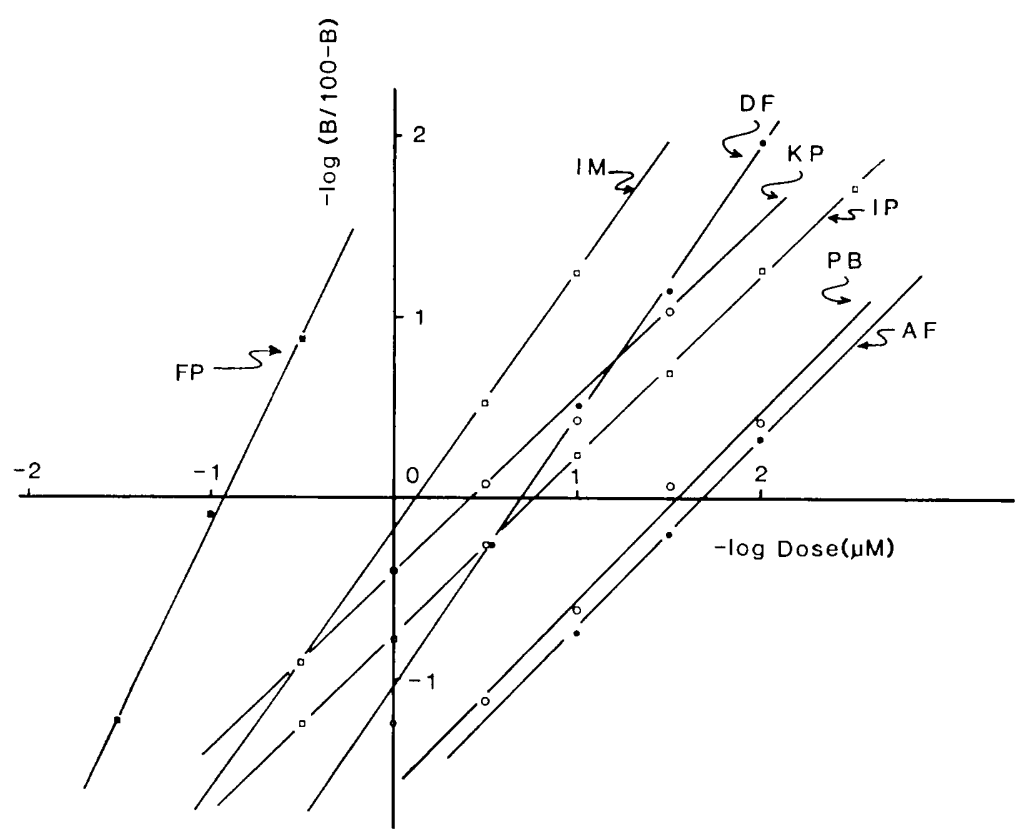

Fig. 2. Hill plot analysis for inhibition of cyclooxygenase activity by various NSAIDs. B is the \% inhibition of cyclooxyganase activity. 
oxygenase. Since the Hill's coefficient for PB was approximately 1.0 in this study, probably PB inhibits the above two reactions to the same degree at the same dose.

Time dependent inhibition of PGs synthesis by NSAIDs: Although several NSAIDs have been reported to cause a time-dependent inhibition of cyclooxygenase, details of this mechanism are not yet clear. In this study, greater inhibition of enzyme activity was observed by preincubation of the enzyme with IM, DF or FP prior to assaying the activity. Time-dependently, the inhibition curves of IM and FP for the cyclooxygenase were significantly shifted to a low dose of the drugs in a gentle slope in proportion to the preincubation time (Fig. 3). These changes in the inhibition curve reached the maximum following preincubation for $10 \mathrm{~min}$, and at this time, the Hill's coefficient of the curve dropped to approximately 1.0 from clearly more than 1.5. Therefore, timedependent inhibition of the enzyme activity was observed significantly at a low dose more than at a high dose of the drugs. A similar effect was also observed with DF (data not shown). By preincubation, however, the inhibition curve of IP was altered to a nonsigmoid shape which was different from those of IM and FP (Fig. 4). This alteration was also observed following preincubation with $\mathrm{PB}, \mathrm{AF}, \mathrm{KP}$ and FA, NP, BW755C and $B P$ (data not shown). The time-dependent changes in the inhibitory effect of IM and FP were also observed following prolongation of the incubation time from 2 min to 5 and (a)
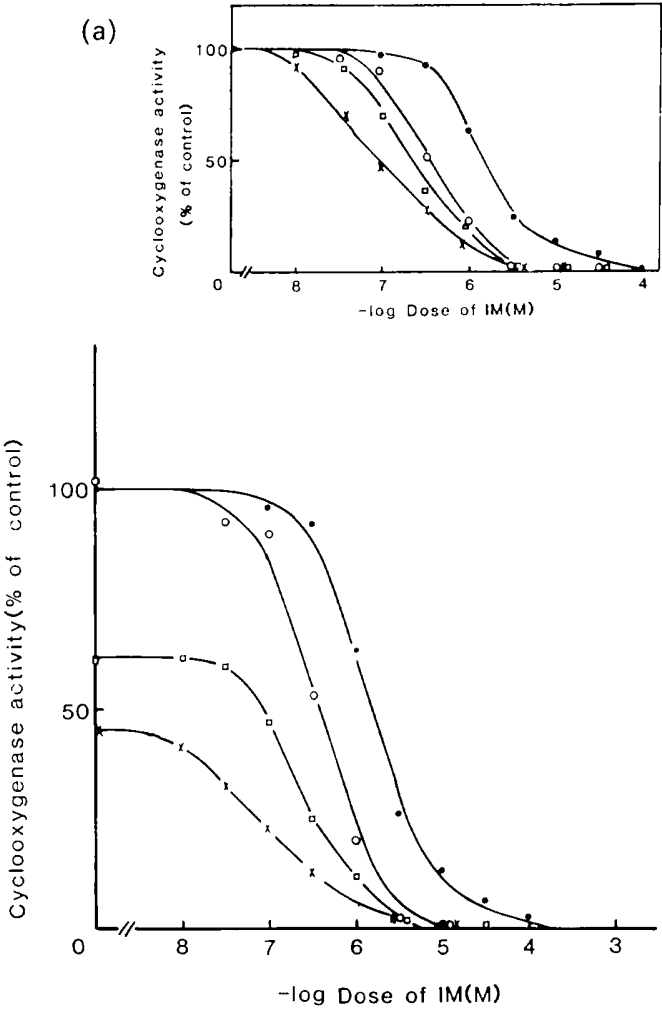

(b)
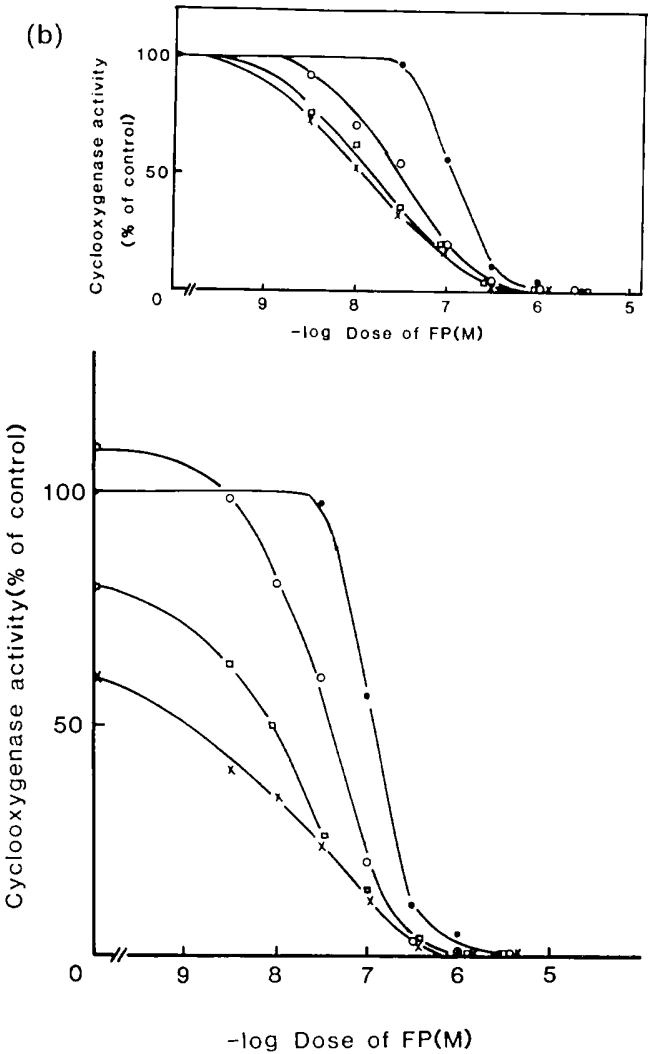

Fig. 3. Effect of preincubation on inhibition of cyclooxygenase activity by IM (a) and FP (b). Enzyme was preincubated for $0 \mathrm{~min}(0), 2 \mathrm{~min}(\bigcirc), 5 \mathrm{~min}(\square)$ and $10 \mathrm{~min}(X)$. Control indicates the activity of the enzyme obtained from the incubation condition of $2 \mathrm{~min}$ and no preincubation with inhibitor. Inset: Enzyme activities were represented as \% of the activity with no inhibitor under each condition. Enzyme was incubated for $2 \mathrm{~min}$ at $30^{\circ} \mathrm{C}$. 
$10 \mathrm{~min}$ (Fig. 5). The Hill's coefficients of the inhibition curves of IM and FP moved toward 1.0 from 1.5 and 2.0 following prolongation of the incubation time. Simultaneously, with the change in the Hill's coefficient, the inhibition curve shifted to the left. By incubating for $10 \mathrm{~min}$, the $1 \mathrm{C} 50$ values for $I M$ and FP obtained from the incubation for $2 \mathrm{~min}$ decreased from $1.5 \mu \mathrm{M}$ to $0.5 \mu \mathrm{M}$ and $0.13 \mu \mathrm{M}$ to $0.014 \mu \mathrm{M}$, respectively.

Concerning the inhibitory effect of IP, the inhibition curve was not altered at all by prolongation of the incubation time (Fig. 6). The potencies of $P B, A F, K P$ and $F A$ also were not altered by prolongation of the incubation time (data not shown). The enzyme was inactivated when preincubation

(a)
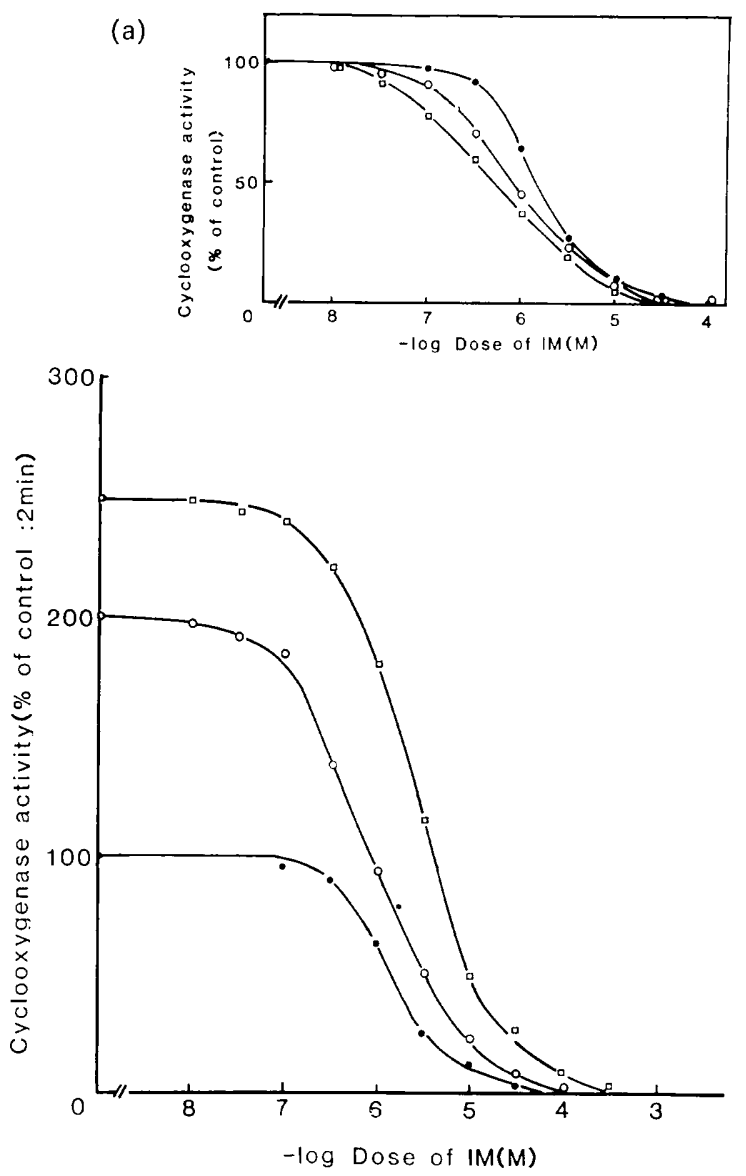

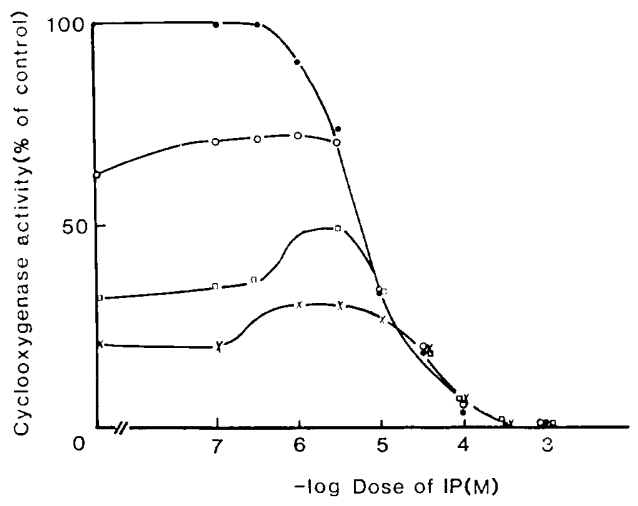

Fig. 4. Effect of preincubation on inhibition of cyclooxygenase activity by IP. Enzyme was preincubated for $0 \min (O), 2 \min (\bigcirc), 5 \min (\square)$ and 10 $\min (X)$. Enzyme was incubated for $2 \mathrm{~min}$ at $30^{\circ} \mathrm{C}$.

(b)
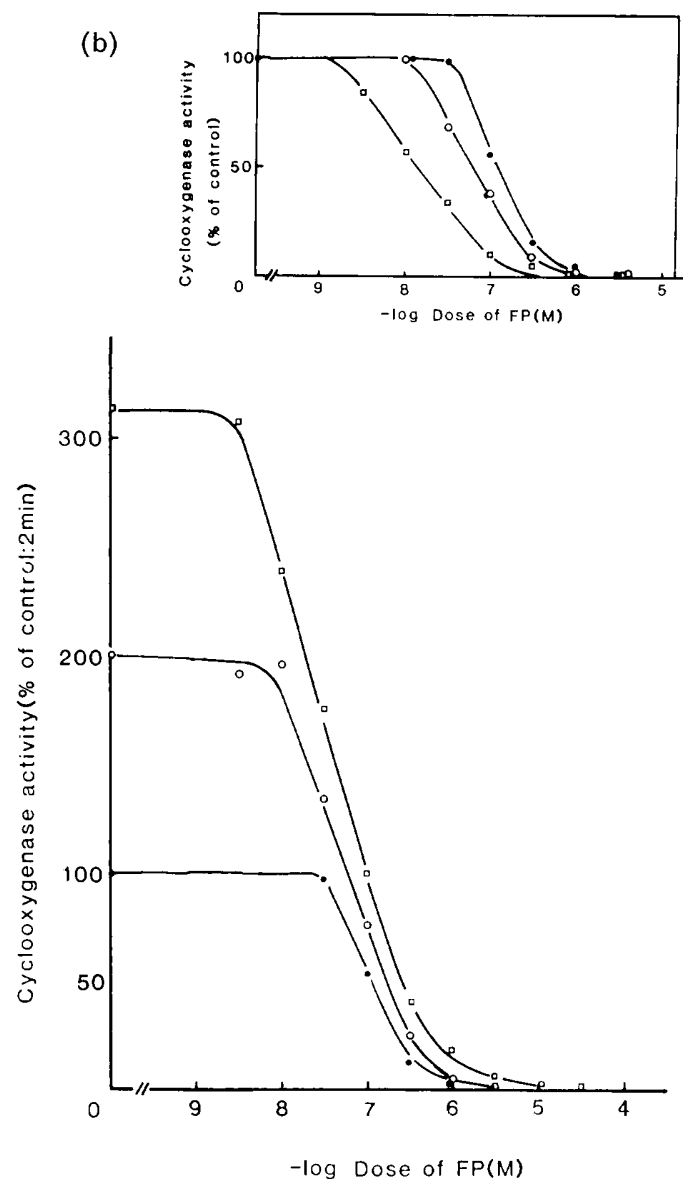

Fig. 5. Effect of prolongation of incubation time on inhibition of cyclooxygenase activity by $I M(a)$ and FP (b). Enzyme was incubated with each inhibitor for $2 \mathrm{~min}(\mathbf{O}), 5 \mathrm{~min}(\mathrm{O})$ and $10 \mathrm{~min}(\square)$ at $30^{\circ} \mathrm{C}$. Inset: Enzyme activities were represented as \% of the activity with no inhibitor under each condition. 

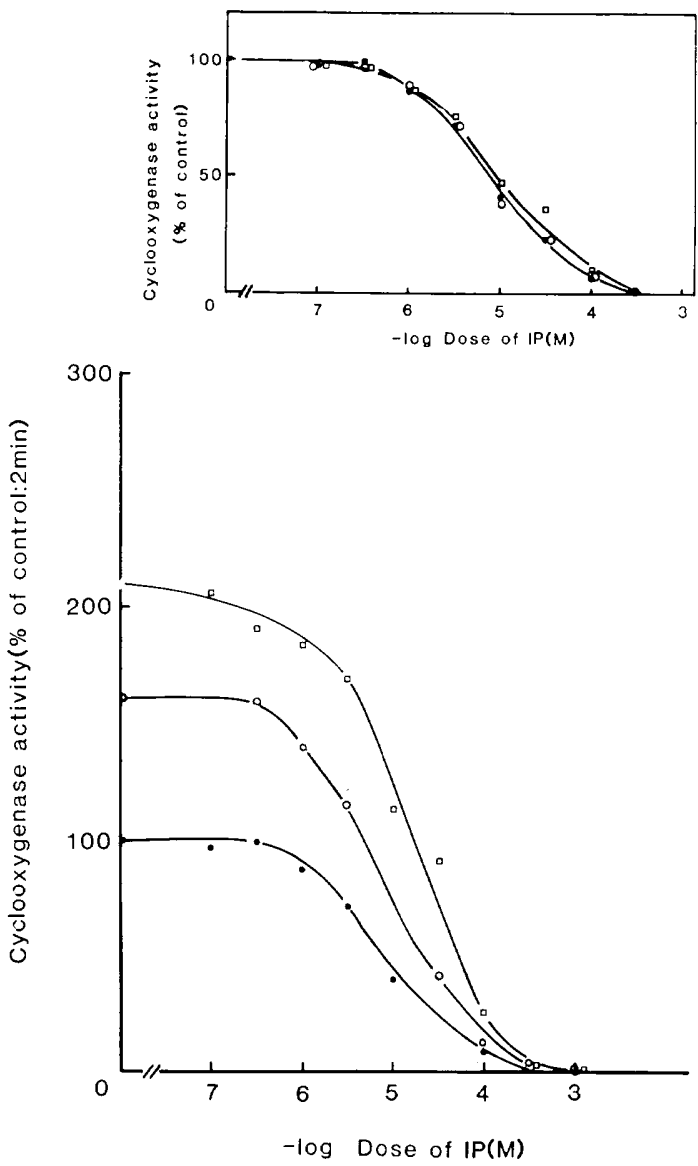

Fig. 6. Effect of prolongation of incubation time on inhibition of cyclooxygenase activity by IP. Enzyme was incubated with IP for $2 \mathrm{~min}(0), 5 \mathrm{~min}(O)$ and $10 \mathrm{~min}(\square)$ at $30^{\circ} \mathrm{C}$. Inset: Enzyme activities were represented as \% of the activity with no inhibitor under each condition.

time was lengthened, but none of these inactivating effects were observed on the enzyme activity by prolongation of the incubation time (Figs. 5 and 6). The difference between the above two conditions is whether the enzyme substrate, arachidonic acid, was present or not. The inactivation mechanism of the enzyme is not clear, but the inactivation was protected by the presence of arachidonic acid, so the catalytic site of the enzyme may be involved in the destruction of the enzyme activity.

Anyhow, the time-dependent inhibitory effect of some NSAIDs on PG synthesis was

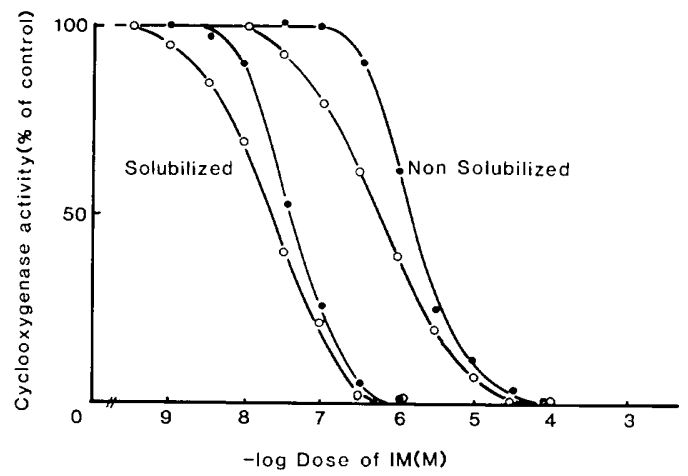

Fig. 7. Effect of solubilization of the enzyme preparation on the time-dependent inhibition of cyclooxygenase activities by IM. Enzyme was incubated with IM for $2 \mathrm{~min}(O)$ and $10 \mathrm{~min}(O)$. Control activities of non-solubilized and solubilized enzymes were $60.3 \pm 3.3$ and $124 \pm 3.6$ pmoles $/ \mathrm{mg}$ protein/min, respectively.

observed when the time of the preincubation and the incubation were lengthened. These results clearly indicate that the drugs for which the Hill's coefficient of the inhibition curve was clearly more than 1.0 reveal a time-dependency in inhibition of the enzyme activity. whereas the drugs for which the Hill's coefficient was 1.0 do not exhibit the time-dependency in inhibitory action. As previously reported by Humes et al. (5), time-dependency in the inhibiting effect of IM was observed from enzyme solubilized by Nonidet P-40. The Hill's coefficient of the inhibition curve of IM dropped to approximately 1.0 from more than 1.0 with a shift of the curve to the left (Fig. 7).

Kinetic analysis of the time dependent inhibition of cyclooxygenase activity by $\mathrm{IM}$ : A Lineweaver-Burk plot of the cyclooxygenase activity was obtained from the reaction time for $2 \mathrm{~min}$. The $K_{m}$ value for arachidonic acid and the $V_{\max }$ value were $25 \mu \mathrm{M}$ and 10.9 nmoles $/ \mathrm{mg}$ protein $/ \mathrm{min}$, respectively. Thirty $\mu \mathrm{M} I \mathrm{M}$ and $50 \mu \mathrm{M} I \mathrm{P}$ inhibited the enzyme activity competitively (Fig. 8). The $K_{i}$ values for $I M$ and IP were 7.8 and 10.2 / $\mathrm{M}$, respectively. By preincubating for $10 \mathrm{~min}$, the $V_{\max }$ and $K_{m}$ values were slightly decreased, but were not significant. The inhibition pattern for IM was not altered by preincubation for $10 \mathrm{~min}$. 

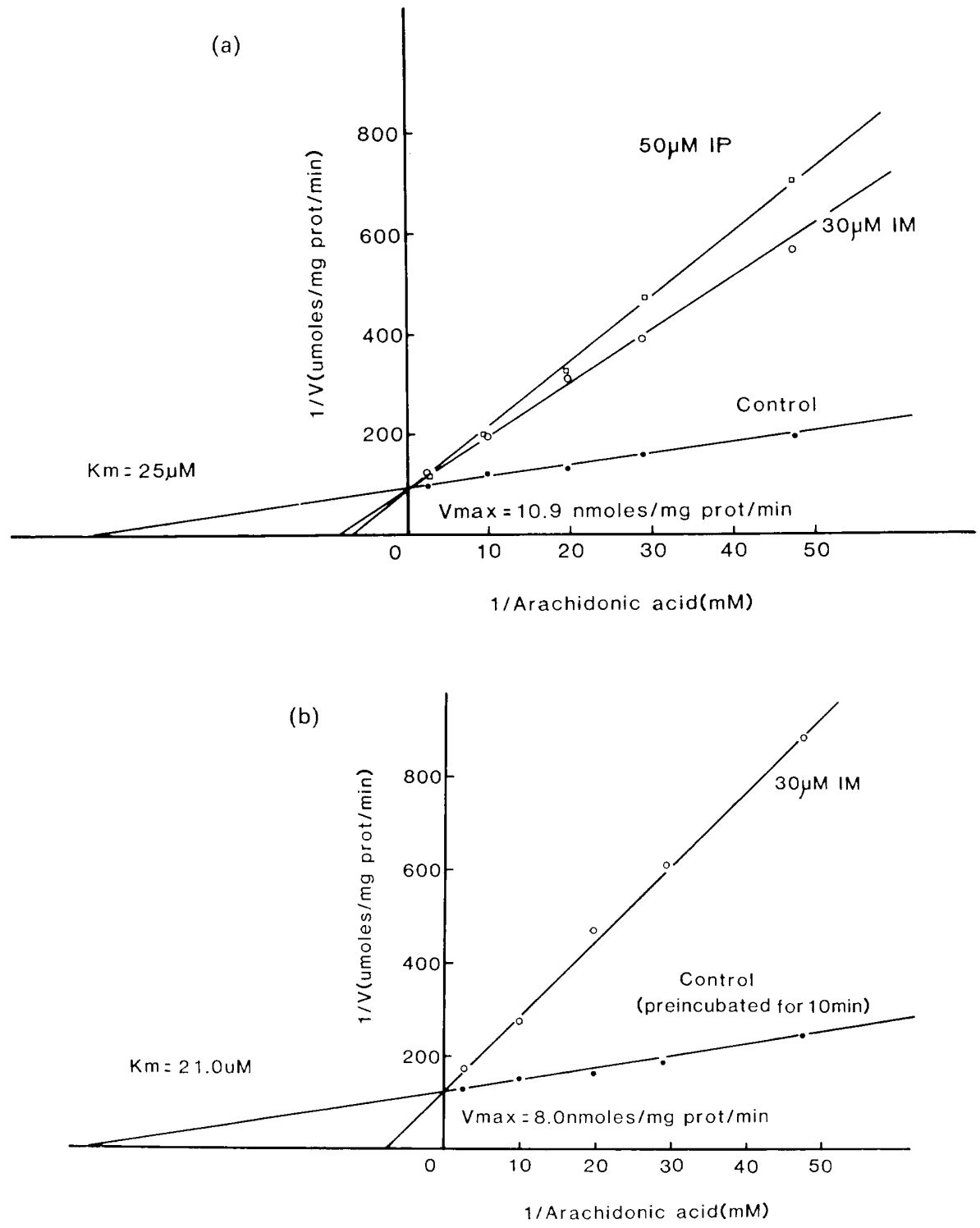

Fig. 8. Double-reciprocal plot of cyclooxygenase activity. Enzyme activities were determined under the condition of no preincubation (a) and preincubation for $10 \mathrm{~min}$ (b) by incubation for $2 \mathrm{~min}$ at $30^{\circ} \mathrm{C}$. Concentrations of from 20 to $400 \mu \mathrm{M}$ of ${ }^{14} \mathrm{C}$-arachidonic acid were used. Each point is the mean value for duplicate determinations.

For arachidonic acid, IM competitively inhibited the enzyme activity (Fig. 8).

The $K_{i}$ value for $I M$ was decreased to $5.3 \mu \mathrm{M}$ from $7.8 \mu \mathrm{M}$ by the preincubation. These results indicate that inhibition of the cyclooxygenase activity by NSAIDs is competitive with respect to arachidonic acid even under the conditions in which the drug showed time-dependent inhibition of cyclooxygenase activity.

Effect of salicylic acid on inhibition of cyclooxygenase by IM and FP: In normal conditions (incubation for $2 \mathrm{~min}$ ), $2 \mathrm{mM}$ salicylic acid had no significant effect on the 


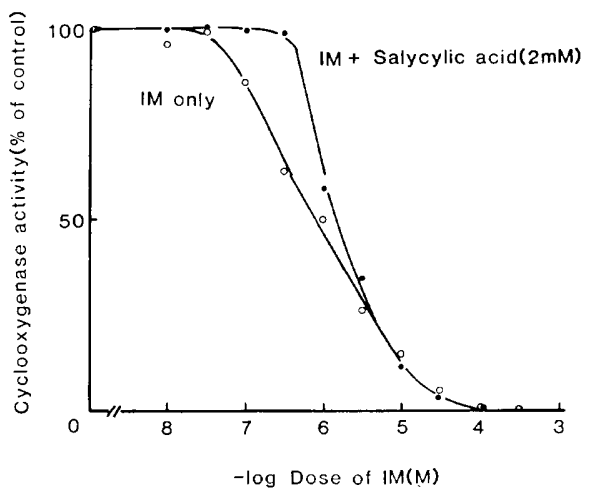

Fig. 9. Protective effect of time-dependent inhibition of IM by salicylic acid. Enzyme was incubated in the absence (O) and presence (O) of $2 \mathrm{mM}$ salicylic acid for $10 \mathrm{~min}$ at $30^{\circ} \mathrm{C}$.

inhibition of cyclooxygenase by IM. In prolonged incubation conditions, in contrast, the presence of $2 \mathrm{mM}$ salicylic acid altered the inhibition curve of $\mathrm{IM}$ to that of normal conditions: that is, there was a shift of the curve to the right with an increase in Hill's coefficient for the curve (Fig. 9). The IC50 values of $\mathrm{IM}$ increased from 0.8 to $1.6 / \mathrm{M}$ following the addition of $2 \mathrm{mM}$ salicylic acid in $10 \mathrm{~min}$ incubation conditions. Similar results were obtained with the timedependent inhibition of cyclooxygenase by FP. Incubation time induced changes in the inhibition curve of FP, that is, a shift to the left and a decrease in the steepness of the slope were inhibited significantly by salicylic acid in a dose-dependent manner (Fig. 10). The dose of salicylic acid required to inhibit the time-dependent decrease in the Hill's coefficient of the curve of FP to $50 \%$ was about $100 \mu \mathrm{M}$. This dose was approximately equal to the one which inhibited the timedependent decrease in the IC50 of FP to the half effect.

\section{Discussion}

The present study demonstrated that the NSAIDs which show time-dependent inhibition of cyclooxygenase activity have different inhibition curves from those of nontime-dependent inhibitors. Since the inhibition curve of the time-dependent inhibitor shifted to the left with the decrease in the

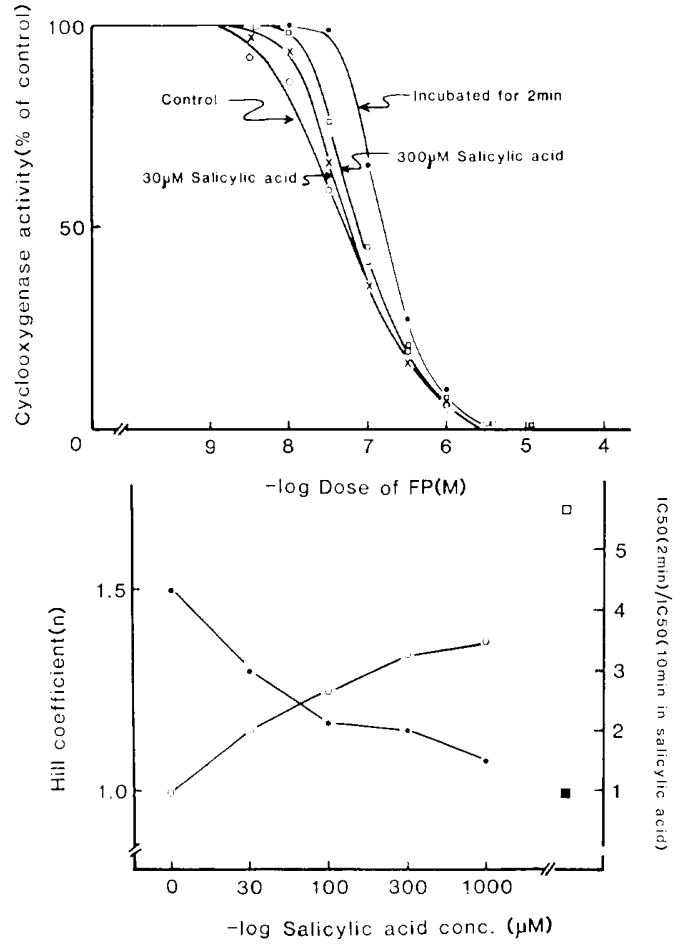

Fig. 10. Dose dependent protective effect of salicylic acid on time-dependent inhibition of cyclooxygenase by FP. Upper fig.: Enzyme was incubated for $2 \mathrm{~min}(\mathbf{O})$ and $10 \mathrm{~min}(\bigcirc)$ in the absence (control) and presence of various concentrations of salicylic acid. Lower fig.: Dose-dependent effect of salicylic acid on the Hill's coefficient (O) and the ratio of IC50 obtained from the incubation condition of $2 \mathrm{~min}$ and $10 \mathrm{~min}$ in the presence of salicylic acid (O), respectively. Each point represents the mean \pm S.E.M. obtained from 4 separate experiments. ( $\square$ ) represents the Hill's coefficient of FP obtained from the incubation time of $2 \mathrm{~min}$ in the absence and presence of $2 \mathrm{mM}$ salicylic acid. represents the ratio of $1 \mathrm{C} 50$ obtained from the incubation condition of $2 \mathrm{~min}$ in the absence and presence of salicylic acid.

Hill's coefficient of the curve from more than 1.0 to 1.0 , time-dependently, the change in the inhibition of cyclooxygenase is more significant at a low dose than at a high dose of the NSAIDs. The time-dependent inhibitions of cyclooxygenase by aspirin and IM were first reported in 1971 (1). Roth et al. (3) suggested that aspirin exerts its timedependent effect by acylation of the cyclo- 
oxygenase, but recently, the acylation has not been considered to be the usual mechanism for all time-dependent inhibitors of NSAIDs (4). Rome and Lands (4) suggested that the time-dependency is due to the irreversible binding of NSAIDs to the enzyme. Our present results, however, did not show noncompetitive inhibition of cyclooxygenase by preincubation of the enzyme with IM. Furthermore, time-dependent ${ }^{14} \mathrm{C}$-IM binding to the enzyme was not observed in this study. Stanford et al. also showed noncovalent binding of ${ }^{14} \mathrm{C}-\mathrm{IM}$ to cyclooxygenase (12). Considering these data, time-dependent inhibition of cyclooxygenase activity is not due to the irreversible binding. but due to the structural features of the NSAIDs as previously suggested by Rome and Lands (4). In the present study, it is noteworthy that the Hill's coefficients of time-dependent and non-time-dependent NSAIDs are not the same when the timedependency is not observed. Furthermore, the Hill's coefficient of the time-dependent one approaches that of the non-timedependent one, time-dependently, and these changes are protected by salicilic acid.

These results indicated that the interactions of the enzyme and the drugs are not the same for the time-dependent and for the non-time dependent NSAIDs in the beginning, but time-dependently, the mode of the timedependent NSAIDs becomes similar to that of the non-time-dependent NSAIDs. For the first interaction of the enzyme and the timedependent NSAIDs, structural requirements for the NSAIDs have been suggested (4); and for the time-dependent process, some models, namely, chemical and allosteric changes, were considered $(4,5)$. In view of the structural requirements, Rome and Lands (4) suggested the combined presence of a halogen and a free carboxylic acid group for the time-dependent inhibitory effect. In the present study, the time-dependency was observed only with drugs containing halogen and a free carboxylic acid group in their structure, but AF which has these two groups did not show any time-dependency. So, the presence of halogen and a free carboxylic acid group in the structure of NSAIDs is probably not sufficient, but is essential for the time- dependent effect of NSAIDs.

The presence of multiple sites on cyclooxygenase which react with NSAIDs was first discovered in the action of NSAIDs by Humes et al. (5). They suggested the existence of at least two distinct sites on the cyclooxygenase, the catalytic site and supplementary site, with which the NSAIDs may react, and salicylic acid and diflunisal may react with the supplementary site and protect the effect of $I M$. In this study, salicylic acid altered the time-dependent process of IM without having any effect on non-timedependent inhibition. They also reported the suppression of the IM effect by salicylic acid at all the times studied. These differences appeared to be due to the difference in the enzyme preparation used: we used bovine seminal vesicle microsomal fraction (BSVM). and they used ram vesicle microsomal fraction (RSVM).

Time-dependent inhibition of cyclooxygenase by $\mathrm{IM}$ reached a plateau within $60 \mathrm{sec}$ in the ram enzyme, while in the bovine enzyme, the time-dependency was not observed within $120 \mathrm{sec}$, and $10 \mathrm{~min}$ was needed for the time-dependent effect to reach the maximum. The blunting effect of diflunisal on the action of non-timedependent NSAIDs (5) does not coincide with our finding that salicylic acid did not have any effect on the inhibition of IP. We cannot explain in detail the difference in these mechanisms at the present time, but different effects of $P G$ synthetase stimulator on the inhibition of cyclooxygenase can be considered as has been reported by Egan et al. (13). The change in the enzyme brought about by the enzyme stimulator which may be involved in the interaction between the enzyme and the NSAIDs effect may contribute to the effect of diflunisal and salicylic acid on the non-time-dependent NSAIDs. Recently, prevention of the inhibitory effect of $\mathrm{IM}$ on platelet cyclooxygenase by salicylic acid was also observed in vivo (14), so that the time-dependent inhibition of PG synthesis in vitro probably indicates an in vivo effect of the NSAIDs.

In conclusion, the differences between the two classes of NSAIDs, time-dependent and non-time-dependent drugs, were 
distinctly seen in the steepness of the slope of the inhibition curve of cyclooxygenase. The time-dependent degree of inhibition of NSAIDs dependent on the Hill's coefficient of the inhibition curve and is important for the potency of cyclooxygenase inhibition in addition to the affinity for the catalytic site of the enzyme.

\section{References}

1 Vane, J.R.: Inhibition of prostaglandin synthesis as a mechanism of action of aspirin-like drugs. Nature 231, 232-233 (1971)

2 Smith, W.L. and Lands, W.E.M.: Stimulation and blockade of prostaglandin biosynthesis. J. Biol. Chem. 246, 6700-6702 (1971)

3 Roth, G.J., Stanford, N. and Majerus, P.W.: Acetylation of prostaglandin synthase by aspirin. Proc. Nat1. Acad. Sci. U.S.A. 72, 3073-3076 (1975)

4 Rome, L.H. and Lands, W.E.M.: Structural requirements for time-dependent inhibition of prostaglandin biosynthesis by anti-inflammatory drugs. Proc. Natl. Acad. Sci. U.S.A. 72, 48634865 (1975)

5 Humes, J.L., Sadowski, S.J. and Kuehl, F.A., Jr.: Multiple sites of prostaglandin cyclooxygenase are determinants in the action of nonsteroidal antiinflammatory agents. Proc. Natl. Acad. Sci. U.S.A. 78, 2053-2056 (1981)

6 Parkes, D.G. and Eling, T.E.: Characterization of prostaglandin synthesis in guinea pig lung. Isolation of new prostaglandin derivative from arachidonic acid. Biochemistry 13, 2598-2604 (1974)
7 Yanagi, Y. and Komatsu, T.: Inhibition of prostaglandin biosynthesis by SL-573. Biochem. Pharmacol. 25, 937-941 (1976)

8 Lowry, O.H., Rosebrough, N.J., Farr, A.L. and Randall, R.J.: Protein measurement with the Folin phenol reagent. J. Biol. Chem. 193, 265275 (1951)

9 Ohki, S., Ogino, N., Yamamoto, S. and Hayaishi, O.: Prostaglandin endoperoxide $E$ isomerase from bovine vesicular gland microsome, a glutathione-regulation enzyme. J. Biol. Chem. 252, 890-895 (1977)

10 Ohki, S., Ogino, N., Yamamoto, S. and Hayaishi, O.: Prostaglandin hydrdperoxidase, an integral part of prostaglandin endoperoxide synthetase from bovine vesicular gland microsomes. J. Biol. Chem. 254, 829-836 (1979)

11 Mizuno, K., Yamamoto, S. and Lands, W.E.M.: Effect of nonsteroidal anti-inflammatory drugs on fatty acid cyclooxygenase and prostaglandin hydroperoxidase activities. Prostaglandins 23, 743-757 (1982)

12 Stanford, N., Roth, G.J., Shen, T.Y. and Wajerus, P.W.: Lack of covalent modification of prostaglandin synthetase (cyclooxygenase) by indomethacin. Prostaglandins 13, 669-675 (1977)

13 Egan, R.H., Humes, J.L. and Kuehl, F.A., Jr.: Different effects of prostaglandin synthetase stimulators on inhibition of cyclooxygenase. Biochemistry 17, 2230-2233 (1978)

14 Cerletee, C., Livio, M. and de Gaetano, G.: Non-steroidal anti-inflammatory drugs react with two sites on platelet cyclo-oxygenase. Evidence from in vivo drug interaction studies in rat. Biochim. Biophys. Acta 714, 122-128 (1981) 